\title{
FORMAÇÃO DE MUDAS DE QUIABEIRO COM DIFERENTES SUBSTRATOS ORGÂNICOS E BIOFERTILIZANTE
}

\section{OKRA SEEDLINGS TRAINING WITH DIFFERENT SUBSTRATES ORGANIC AND FERTILIZER}

\section{OKRA PLÁNTULAS ENTRENAMIENTO CON DIFERENTES SUSTRATOS ORGÁNICOS Y FERTILIZANTES}

\author{
Samara Patrícia de OLIVEIRA ${ }^{1}$ \\ Edinete Nunes de MELO ${ }^{2}$ \\ Dalila Regina Mota de MELO $^{3}$ \\ Fabiana Xavier COSTA ${ }^{4}$ \\ Evandro Franklin de MESQUITA ${ }^{5}$
}

RESUMO: Objetivou-se com este trabalho, avaliar os efeitos do emprego de diferentes substratos a base de solo, húmus de minhoca e pó de madeira em diferentes proporções em associação com biofertilizante líquido na formação de mudas de quiabeiro. O delineamento experimental foi inteiramente casualizado, em esquema fatorial 4 x 5 com cinco repetições, sendo 4 doses de biofertilizante: $(0,0 ; 5 ; 10$ e $15 \% \mathrm{v} / \mathrm{v})$ e cinco tipos de substratos: substrato $1\left(\mathrm{~S}_{1}\right): 100 \%$ de solo, substrato $2\left(\mathrm{~S}_{2}\right): 100 \%$ de húmus, substrato $3\left(\mathrm{~S}_{3}\right): 50 \%$ de solo $+25 \%$ de húmus $+25 \%$ de pó de madeira, substrato $4\left(\mathrm{~S}_{4}\right): 50 \%$ de pó de madeira $+25 \%$ de húmus $+25 \%$ de solo, e substrato 5 $\left(\mathrm{S}_{5}\right): 75 \%$ de pó de madeira $+12 \%$ de húmus $+12 \%$ de solo). A semeadura foi realizada em sacos de polietileno que foram preenchidos com $1 \mathrm{~L}$ de cada substrato. De maneira geral, $\mathrm{O}$ substrato $\mathrm{S}_{1}$ (100\% solo) e $S_{2}$ (100\% húmus) de esterco influenciaram de forma positiva o crescimento e biomassa seca em mudas do quiabeiro. $\mathrm{O}$ substrato $\mathrm{S}_{5}(75 \%$ de húmus+ $12,5 \%$ de solo $+12,5 \%$ de húmus de minhoca) foi inadequado para formação de mudas do quiabeiro.

Palavras-chave: Abelmoschus esculentus (L.) Moench; resíduos de substratos; Olericultura

\footnotetext{
ABSTRACT: The objective of this study was to evaluate the effects of using different substrates soil base, earthworm compost and wood dust in different proportions in combination with liquid biofertilizer in the formation of okra seedlings. The experimental design was completely

1 Universidade Estadual da Paraíba. Departamento de Ciências Agrárias e Exatas. Área de Ciências Agrárias. samarapatriciaoliveira123@hotmail.com

${ }^{2}$ Universidade Estadual da Paraíba. Departamento de Ciências Agrárias e Exatas. Área de Ciências Agrárias. edy_anjos@hotmail.com

3 Universidade Estadual da Paraíba. Departamento de Ciências Agrárias e Exatas. Área de Ciências Agrárias. dalilaregina@hotmail.com

${ }^{4}$ Prof. Dra. do Departamento de Agrárias e Exatas da Universidade Estadual da Paraíba - UEPB/Campus IV.

Bióloga, Doutorado em Recursos Naturais. CEP 58884-000 - Catolé do Rocha - Paraíba - Brasil. fabyxavierster@gmail.com

${ }^{5}$ Universidade Estadual da Paraíba. Departamento de Ciências Agrárias e Exatas. Área de Ciências Agrárias. elmesquita4@uepb.edu.br
} 
randomized in a factorial $4 \times 5$ with five replications and 4 doses of biofertilizers: $(0.0,5,10$ and $15 \% \mathrm{v} / \mathrm{v}$ ) and five types of substrates: Substrate 1 (S1): $100 \%$ soil substrate 2 (S2): $100 \%$ humus substrate 3 (S3): $50 \%$ ground $+25 \%+25 \%$ humus wood dust substrate 4 (S4): $50 \%$ powder wood $+25 \%+25 \%$ humus soil and substrate 5 (S5): $75 \%$ of wood powder $+12 \%+12 \%$ humus soil). The seeds were sown in plastic bags that were filled with $1 \mathrm{~L}$ of each substrate. In general, substrate S1 (100\% ground) and S2 (100\% humus) manure positively influence growth and biomass dried in okra seedlings. The S5 substrate (75\% humus $+12.5 \%+12.5 \%$ soil earthworm humus) was inadequate for training okra seedlings.

Key words: .Abelmoschus esculentus (. L) Moench; substrate; waste Horticulture

RESUMEN: El objetivo de este estudio fue evaluar los efectos del uso de diferentes sustratos base de suelo, lombricompuesto y polvo de madera en diferentes proporciones en combinación con biofertilizante líquido en la formación de plántulas okra. El diseño experimental fue completamente al azar en un factorial 4 x 5 con cinco repeticiones y 4 dosis de biofertilizantes: $(0,0,5,10$ y $15 \%$ v / v) y cinco tipos de sustratos: Sustrato 1 (S1): $100 \%$ sustrato de suelo 2 (S2): $100 \%$ sustrato humus 3 (S3): $50 \%$ suelo $+25 \%+25 \%$ sustrato polvo de madera humus 4 (S4): $50 \%$ de polvo de madera $+25 \%+25 \%$ humus del suelo y el sustrato 5 (S5): $75 \%$ de la madera en polvo $+12 \%+12 \%$ de suelo humus). Las semillas se sembraron en bolsas de plástico que fueron llenados con $1 \mathrm{~L}$ de cada sustrato. En general, el sustrato S1 (100\% del suelo) y S2 (100\% humus) estiércol influir positivamente en el crecimiento y la biomasa seca de plántulas okra. El sustrato S5 $(75 \%$ humus $+12,5 \%+12,5 \%$ humus de lombriz suelo) era insuficiente para las plántulas formación okra.

Palabras-clave: Abelmoschus esculentus (L) Moench; residuos de sustrato; Horticultura

\section{Introdução}

A cultura do quiabo (Abelmoschus esculentus (L.) Moench), originário da África, pertencente à família Malvaceae, é tradicionalmente cultivado em regiões tropicais, com destaque para a variedade Santa Cruz 47 largamente cultivada no Brasil (GALATI et al., 2013), bem como no estado da Paraíba. Para Souza et al. (2014), a produção de mudas nesta cultura constitui-se numa das etapas mais importantes do sistema produtivo, influenciando diretamente o desempenho nutricional e produtivo, refletindo na precocidade, no desenvolvimento vegetativo e na duração do período de produção.

O quiabo é o fruto da Abelmoschus esculentus, uma planta da família da malva (Malvaceae). O quiabo é uma hortaliça de clima quente e originária da África, tendo sido trazida para o Brasil pelos escravos. Desde então, a hortaliça passou a fazer parte da culinária brasileira; um exemplo disso é o frango com quiabo, um símbolo da culinária de Minas 
Gerais.Na verdade, o quiabo é uma cápsula fibrosa cheia de sementes que é colhida antes de chegar à fase de maturação. Geralmente, a hortaliça é verde, possui uma forma de cápsula, é seca e apresenta um líquido viscoso em seu interior.

A produção de mudas é uma da fase mais importantes da condução do pomar, visto que mudas mais vigorosa influenciam diretamente na produtividade da cultura (TRINDADE et al., 2000). No entanto, a qualidade da muda depende de inúmeros fatores como clima, potencial genético do porta-enxerto, substratos, irrigação e cuidados fitossanitários.

Para Zietemann e Roberto (2007), o substrato destina-se a sustentar as plantas durante o enraizamento e servir de fonte de nutrientes para as plantas, além de fornecer aeração adequada, e capacidade de retenção de líquido satisfatória para oferecer umidade adequada a muda. Os referidos autores sugerem substratos como utilizando mistura de solo (Latossolo) + matéria orgânica (esterco de curral) + areia fina $(2: 1: 1)$, Plantmax ${ }^{\circledR}$ e fibra de coco Sococo® No entanto, com a Lei n ${ }^{\circ} 10.711$, de 05/08/2003 regulamenta a produção de mudas no nosso pais com finalidade de controlar a infestação de praga e doenças. Entretanto, é indispensável o desenvolvimento de substratos que atendam as exigências nutricionais das plantas e de em suporte físico ideal as plantas, que pode ocorrer mediante a substituição dos fertilizantes químicos de origem sintética do sistema convencional, por biofertilizantes líquidos associados com outros adubos orgânicos. Haja vista, que testes realizados in vivo comprovaram que o biofertilizante líquido, é um excelente nematicida e larvicida, agindo de maneira fumigante e asfixiante quando em contato com nematóides e larvas existentes em solos muito contaminados (VAIRO e AKIBA, 1996).

Para Malavolta (1989), o biofertilizante é um composto biológico completo de nutrientes essenciais, que pode ser disponibilizado para as plantas aplicado no solo, na irrigação ou por via foliar, possibilitando a obtenção de boas produções e a obtenção de frutos com adequada qualidade comercial e sanitária. Alguns estudos têm demonstrado que o uso de biofertilizantes na formulação do substrato pode atenuar as possíveis deficiências nutricionais e favorecer o crescimento das plantas na fase de produção de mudas (SÁ et al., 2013; DANTAS et al.,2014).

O volume do recipiente e o tipo de substrato são os primeiros aspectos que devem ser investigados para garantir a produção de mudas de excelente qualidade. $O$ volume do recipiente deve ser tal que permita o desenvolvimento do sistema radicular sem restrições significativas, durante o período de permanência no viveiro. Da mesma forma, o substrato exerce influência marcante na arquitetura do sistema radicular e no estado nutricional das 
plantas, afetando profundamente a qualidade das mudas (CARNEIRO, 1983). Portanto, esses fatores são de fundamental importância para obtenção de mudas de excelente qualidade.

Objetivou-se com este trabalho avaliar os efeitos do emprego de diferentes substratos a base de solo, húmus de minhoca e pó de madeira em diferentes proporções em associação com biofertilizante líquido na formação de mudas de quiabeiro.

\section{Material e métodos}

O experimento foi conduzido na UEPB- campus IV, no município de Catolé do Rocha entre 26 de junho a 28 de julho de 2014, Paraíba (6²’38' de latitude sul, 3744'48” de longitude oestes e altitude de $275 \mathrm{~m}$ ). O viveiro foi cercado e coberto com tela permitindo $50 \%$ de luminosidade e boa ventilação em seu interior.

No preparo do substrato foram-se utilizado de amostras de Neossolo Flúvico Eutrófico do qual foram coletadas as amostras de solo na camada superficial dos solos $(0-20 \mathrm{~cm})$, estas foram colocadas para secar a ar, destorroadas e peneirada com peneira com malha de $2 \mathrm{~mm}$ e segundo metodologia propostas pela EMBRAPA (2006) foi realizada a caracterização físicoquímicas da mesma no Laboratório de Irrigação e Salinidade (LIS) do Centro de Tecnologia e Recursos Naturais da Universidade Federal de Campina Grande (UFCG) (Tabela 2). Ainda para o preparo do substrato foi utilizado de amostras de húmus de minhoca, o qual também passou pelos mesmos procedimentos de secagem, foi destorroado e peneirado em peneira com malha de $2 \mathrm{~mm}$ e caracterizado quimicamente no Laboratório de Irrigação e Salinidade (LIS) do Centro de Tecnologia e Recursos Naturais da Universidade Federal de Campina Grande (UFCG), seguindo metodologia propostas pela EMBRAPA (2006) (Tabela 1).

Tabela 1. Características químicas do solo (Neossolo Flúvico Eutrófico) de textura francoarenosa da área do experimento UEPB, Catolé do Rocha-PB, 2014.

\begin{tabular}{|c|c|c|c|c|c|c|c|c|c|c|c|c|c|}
\hline $\mathrm{Ph}$ & $\mathrm{Ca}$ & $\mathrm{Mg}$ & $\mathrm{Al}$ & $\mathrm{H}+\mathrm{Al}$ & $\mathrm{P}$ & $\mathrm{K}$ & $\mathrm{Na}$ & $\mathrm{Fe}$ & $\mathrm{Zn}$ & $\mathrm{Cu}$ & $\mathrm{Mn}$ & B & M.O \\
\hline$(1: 2,5)$ & -------c & $\mathrm{ol}_{\mathrm{c}} \cdot \mathrm{dr}$ & ----- & & $\overline{\mathrm{ag} \mathrm{d}}$ & & ----- & ----- & mg.dn & & --- & & $\%$ \\
\hline 6,84 & 5,25 & 1,15 & 0,0 & 1,08 & 49 & 280 & 64 & 59,69 & 4,05 & 3,83 & 53,98 & 6,45 & 1,1 \\
\hline
\end{tabular}

Laboratório de análise de solo, água e planta, Natal-RN, 2013.

Após a caracterização química do húmus de minhoca usado na mistura dos substratos de acordo com os tratamentos, conforme Tabela 2. 
Tabela 2. Características químicas do húmus de minhoca, utilizados no experimento.UEPB, Catolé do Rocha-PB,2014.

\begin{tabular}{|c|c|c|c|c|c|c|c|c|}
\hline \multirow{3}{*}{ Húmus de minhoca } & $\mathrm{pH}$ & $\mathrm{P}$ & $\mathrm{K}$ & $\mathrm{Ca}$ & $\mathrm{Mg}$ & $\mathrm{Na}$ & $\mathrm{Al}$ & $\mathrm{H}$ \\
\hline & $\mathrm{H}_{2} \mathrm{O}$ & $\mathrm{mg} \mathrm{dm}{ }^{-3}$ & & ---- & $----c$ & $1-$ & 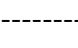 & \\
\hline & 7,38 & 55 & 1,41 & 35,40 & 19,32 & 1,82 & 0,00 & 0,00 \\
\hline
\end{tabular}

Análises realizadas no Laboratório de Irrigação e Salinidade (LIS/DEAg/CTRN/UFCG), Campina Grande-PB ,2013.

O biofertilizante enriquecido com leguminosa e pó de pedra, a base de esterco bovino foi produzido, de forma anaeróbia, em recipiente plástico, com capacidade para $240 \mathrm{~L}$, contendo uma mangueira ligada a uma garrafa plástica transparente com água para retirada do gás metano produzido no interior do recipiente pela fermentação das bactérias anaeróbias. $\mathrm{O}$ material utilizado para produção do referido fertilizante constou de $70 \mathrm{~kg}$ de esterco verde de vacas em lactação e de $120 \mathrm{~L}$ de água, além de $5 \mathrm{~kg}$ de açúcar e $5 \mathrm{~L}$ de leite para aceleração do metabolismo das bactérias, mais $5 \mathrm{~kg}$ de matéria verde de leguminosa (feijão) e 4 kg de pó de pedra (Tabela 3 ).

O qual permaneceu sob condições de fermentação anaeróbica constante durante 60 dias garantindo a decomposição do insumo. Após o preparo, foram coletadas amostras do biofertilizante e encaminhadas para Laboratório de Irrigação e Salinidade (LIS) do Centro de Tecnologia e Recursos Naturais da Universidade Federal de Campina Grande (UFCG), no qual se realizou a caracterização química da matéria seca do mesmo seguindo metodologia propostas pela EMBRAPA (2006) (Tabela 3).

Tabela 3. Composição química na matéria seca do biofertilizante á base de esterco aos 60 dias após o inicio da fermentação anaeróbia. UEPB, Catolé do Rocha-PB, 2014.

\begin{tabular}{|c|c|c|c|c|c|c|c|c|c|}
\hline $\mathrm{pH}$ & $\mathrm{CE}_{25^{\circ} \mathrm{C}}$ & $\mathrm{Ca}^{+2}$ & $\mathrm{Mg}^{+2}$ & $\mathrm{Na}^{+1}$ & $\mathrm{~K}^{+1}$ & $\mathrm{Cl}^{-1}$ & $\mathrm{CO}_{3}{ }^{2-}$ & $\mathrm{HCO}_{3}{ }^{-}$ & $\mathrm{SO}_{4}{ }^{2-}$ \\
\hline & $\mathrm{dS} \mathrm{m}^{-1}$ & & $\ldots \ldots$ & $\ldots \ldots$ & $\mathrm{cmol}_{\mathrm{c}}$ & $\cdots$ & …......... & .......... & \\
\hline 6,34 & 8,08 & 3,71 & 2,40 & 3,27 & 1,69 & 4,59 & 0,43 & 2,03 & 1,02 \\
\hline
\end{tabular}

$\mathrm{CE}=$ condutividade elétrica do extrato de saturação. Análises realizadas no Laboratório de Irrigação e Salinidade (LIS/DEAg/CTRN/UFCG), Campina Grande-PB, 2013.

Como a água da região Semiárida apresenta certa salinidade, a água utilizada na irrigação foi analisada no Laboratório de Irrigação e Salinidade (LIS) do Centro de Tecnologia e Recursos Naturais da Universidade Federal de Campina Grande (UFCG) e 
apresentou condutividade elétrica de $0,8 \mathrm{dS} \mathrm{m}^{-1}$ sendo considerada apropriada para a irrigação da quiabeiro (CAVALCANTE et al., 2010). As características químicas da água estão apresentadas na (Tabela 4).

Para a irrigação foi utilizada água de poço amazônico (Tabela 4), sendo realizada com um volume uniforme de água às plantas, em função da evapotranspiração média no tratamento testemunha, obtida por pesagem. $\mathrm{O}$ volume aplicado $(\mathrm{Va})$ por recipiente foi obtido pela diferença entre a média do peso dos recipientes em condição de máxima retenção de água $\left(P_{c c}\right)$, o qual foi determinado saturando-se os recipientes com água e submetendo-os à drenagem; quando o volume drenado estiver reduzindo, os recipientes foram pesados, obtendo-se o valor do $P_{c c}$ quando o peso dos recipientes com substrato for constante; e o peso médio dos recipientes na condição atual $\left(P_{a}\right)$, dividido pelo número de recipientes $(\mathrm{n})$, como indicado na equação 1:

$$
V a=\frac{P c c-P a}{n}(1)
$$

Tabela 4. Características químicas da água utilizada para utilizada no experimento.

\begin{tabular}{|c|c|c|c|c|c|c|c|c|c|c|}
\hline $\mathrm{pH}$ & $\mathrm{CE}_{25^{\circ} \mathrm{C}}$ & $\mathrm{Ca}^{+2}$ & $\mathrm{Mg}^{+2}$ & $\mathrm{Na}^{+1}$ & $\mathrm{~K}^{+1}$ & $\mathrm{Cl}^{-1}$ & $\mathrm{CO}_{3}{ }^{2-}$ & $\mathrm{HCO}_{3}^{-}$ & $\mathrm{SO}_{4}^{2-}$ & RAS \\
\hline & $\mathrm{dS} \mathrm{m}^{-1}$ & & $\ldots$ & N. & .mmol & & $\ldots$ & ...... & & $\left(\mathrm{mmol}_{\mathrm{c}} \mathrm{L}^{-1}\right)^{1 / 2}$ \\
\hline 7,53 & 0,80 & 2,30 & 1,56 & 4,00 & 0,02 & 3,90 & 0,57 & 3,85 & 0,00 & 2,88 \\
\hline
\end{tabular}

Análises realizadas no Laboratório de Irrigação e Salinidade (LIS/DEAg/CTRN/UFCG), Campina Grande-PB.

O delineamento experimental utilizado foi inteiramente casualizado, em esquema fatorial 4 x 5 com cinco repetições, sendo 4 doses de biofertilizante: $(0,0 ; 5 ; 10$ e $15 \%$ v/v) e cinco tipos de substratos: substrato $1\left(\mathrm{~S}_{1}\right): 100 \%$ de solo, substrato $2\left(\mathrm{~S}_{2}\right): 100 \%$ de húmus, substrato $3\left(\mathrm{~S}_{3}\right): 50 \%$ de solo $+25 \%$ de húmus $+25 \%$ de pó de madeira, substrato $4\left(\mathrm{~S}_{4}\right): 50 \%$ de pó de madeira $+25 \%$ de húmus $+25 \%$ de solo, e substrato $5\left(\mathrm{~S}_{5}\right): 75 \%$ de pó de madeira + $12 \%$ de húmus $+12 \%$ de solo), , perfazendo 100 unidades experimentais.

A semeadura foi realizada em sacos de polietileno com $12 \mathrm{~cm}$ de largura, $25 \mathrm{~cm}$ de altura e $0,008 \mathrm{~cm}$ de espessura, furados lateralmente, que foram preenchidos com $1 \mathrm{~L}$ de cada substrato, sendo colocadas quatro sementes por recipiente em 28/07/2014. O desbaste das mudas foi feito aos 11 dias, após a semeadura (DAS), quando as mudas estavam com par de folha definitiva foi o desbaste, deixando a mais vigorosa por recipiente.

O biofertilizante bovino foi aplicado ao solo depois de diluído em água, na proporção de 1:3 (m/v), 24 horas antes da semeadura e 11 dias e 20 dias após semeadura (DAS). 
Após a incorporação do biofertilizante, os recipientes foram irrigados até que o solo atingisse a capacidade de campo (CC), de forma a garantir a efetivação do processo de germinação e de desenvolvimento das plântulas. A variedade de quiabeiro utilizada foi a Santa Cruz.

Aos 30 dias, final do experimento, foram avaliados: a) Altura da planta: obtida do colo à base da folha mais jovem com régua graduada em centímetro; b) Diâmetro do caule: foi determinado com um paquímetro, com as leituras sendo efetuadas a $2 \mathrm{~cm}$ de altura na região do colo de cada planta, nos mesmos períodos estabelecidos para mensuração da altura de plantas (AP);c) Área foliar: foi calculada o comprimento versus largura (x) versus um fator de correção 0,63 .

O material vegetal colhido foi separado em raízes, caules, folhas, posteriormente seco em estufa de circulação de ar a temperatura de $60^{\circ} \mathrm{C}$ até atingir peso constante e pesado. A obtenção da matéria seca total (MST) se deu através da soma dos pesos de cada uma dessas partes (PSC + PSF +PSR). A relação raíz/parte aérea foi calculada pelo coeficiente entre os valores de fitomassa das raízes e os valores de fitomassa da parte aérea da planta obtido no final do experimento.

Os dados foram submetidos à análise de variância, ao nível de significância de $5 \%$. Com base na significância dos dados procedeu aplicação do teste de Tukey, a 5\% de probabilidade, para os fatores qualitativos (Substratos), utilizando o aplicativo SISVAR (FERREIRA, 2011).

\section{Resultados e discussão}

Foi observado efeito significativo dos substratos $(\mathrm{p}<0,001)$ pelo teste $\mathrm{F}$, para as altura da planta (AP), diâmetro caulinar (DC), área foliar (AF), matéria seca da parte aérea (MSPA), matéria seca de raiz (MSR), matéria seca total (MST) e relação raiz parte aérea

Consta-se ainda que não houve efeito significativo referentes aos tratamentos com as doses de biofertilizante bovino, bem como a interação substratos versus doses de biofertilizante bovino para nenhum variável analisada. (Tabela 5). Os resultados obtidos divergem das constatações de DANTAS et al. (2014), os quais observaram efeito significativo dos tratamentos referentes as doses de biofertilizante e substratos (com $25 \%$ e $50 \%$ de esterco bovino) sob o crescimento de mudas de aceroleira. No mesmo raciocínio, os resultados obtidos divergem em parte das constatações de Veras et at. (2014), os quais observaram efeito significativo para os tratamentos com biofertilizante bovino para as variáveis altura da planta, 
diâmetro do caule, número de folhas e peso verde da raiz a nível, no entanto, não foram observados diferença estatística para área foliar e o peso seco do caule em mudas Cajueiro.

Tabela 5. Resumos das análises de variância das variáveis matéria seca da parte aérea (MSPA), matéria seca da raiz (MSR), matéria seca total (MST) e relação raiz/parte aérea (RRPA) demudas de quiabeiro em função da composição do substrato. UEPB, Catolé do Rocha-PB, 2014.

\begin{tabular}{ccccccccc}
\hline \multirow{2}{*}{ FV } & \multirow{2}{*}{ GL } & \multicolumn{7}{c}{ Quadrado Médio } \\
\cline { 3 - 8 } & & AP & DC & AF & MSPA $^{1}$ & MSR $^{1}$ & MST $^{1}$ & RRPA $^{1}$ \\
\hline Dose (D) & 3 & $3,10^{\text {ns }}$ & $0,32^{\text {ns }}$ & $349^{\text {ns }}$ & $0,0195^{\text {ns }}$ & $0,0015^{\text {ns }}$ & $0,0116^{\text {ns }}$ & $0,0300^{\text {ns }}$ \\
\cline { 3 - 9 } Substratos (S) & 4 & $82,70^{* *}$ & $12,33^{* *}$ & $37079^{* *}$ & $0,7892^{* *}$ & $0,1561^{* *}$ & $0,9226^{* *}$ & $0,1523^{* *}$ \\
\cline { 3 - 9 } D x S & 12 & $3,10^{\text {ns }}$ & $0,32^{\text {ns }}$ & $313^{\text {ns }}$ & $0,0083^{\text {ns }}$ & $0,0091^{\text {ns }}$ & $0,0119^{\text {ns }}$ & $0,0416^{\text {ns }}$ \\
\cline { 3 - 9 } Resíduo & 80 & 3.95 & 0,18 & 280 & 0,0098 & 0,0084 & 0,0130 & 0,0476 \\
\hline Coeficiente de Variação & 20,28 & 16,08 & 37,76 & 20,49 & 32,94 & 20,93 & 36,65 \\
\hline \multicolumn{2}{c}{ Média Geral } & 9,81 & 2,68 & 44,32 & 0,40 & 0,27 & 0,57 & 0,59 \\
\hline
\end{tabular}

** $\mathrm{e}^{\mathrm{ns}}$, significativo a $1 \%$ pelo teste $\mathrm{F}$ e não significativo respectivamente; $\mathrm{FV}=$ fonte de variação; $\mathrm{GL}=$ grau de liberdade; ${ }^{1}$ Análise, após transformação de dados $\sqrt{X}$.

Analisando-se a Figura 1 é possível observar que para altura das mudas de quiabeiro, as maiores médias observadas foram para o tratamento $S_{1}$ e $S_{2}$ com valores de 11,18 e $12,14 \mathrm{~cm}$ diferindo estatisticamente dos tratamentos $\mathrm{S}_{4}$ e $\mathrm{S}_{5}$. Esse resultado pode estar relacionado ao maior teor de nutrientes desse substrato formado com 505 e $100 \%$ de húmus de minhoca na composição do substrato. Os resultados encontrados nesse trabalho vem a corroborar com Mello et al. (2000) e Carneiro et al. (2010), os quais afirmam que o tipo de material orgânico influencia na produção final das mudas. Neste mesmo sentido, Menezes Junior et al. (2000) verificaram que os substratos que têm na sua composição material orgânico, apresentam melhores propriedades físicas, químicas e biológica, favorecendo para o melhor crescimento das mudas.

Os resultados obtidos nos substratos $S_{1}$ e $S^{2}$ foram semelhantes as constatações de Erlacher et al. (2013), ao observaram as alturas de mudas de quiabeiro com 12,75 formada no substrato com caroço de açaí triturado fresco sobre o contra piso ficando exposto ao sol e a chuva por 95 dias, sendo revirado uma a duas vezes por semana para homogeneização do material e foi molhado quando necessário de forma a estimular o processo de fermentação e moderada decomposição. 
Figura 1. Altura de mudas de quiabeiro em função de diferentes substratos. ( médias seguidas da mesma letra não difere entre si pelo teste tukey/p<0,05) UEPB, Catolé do Rocha-PB

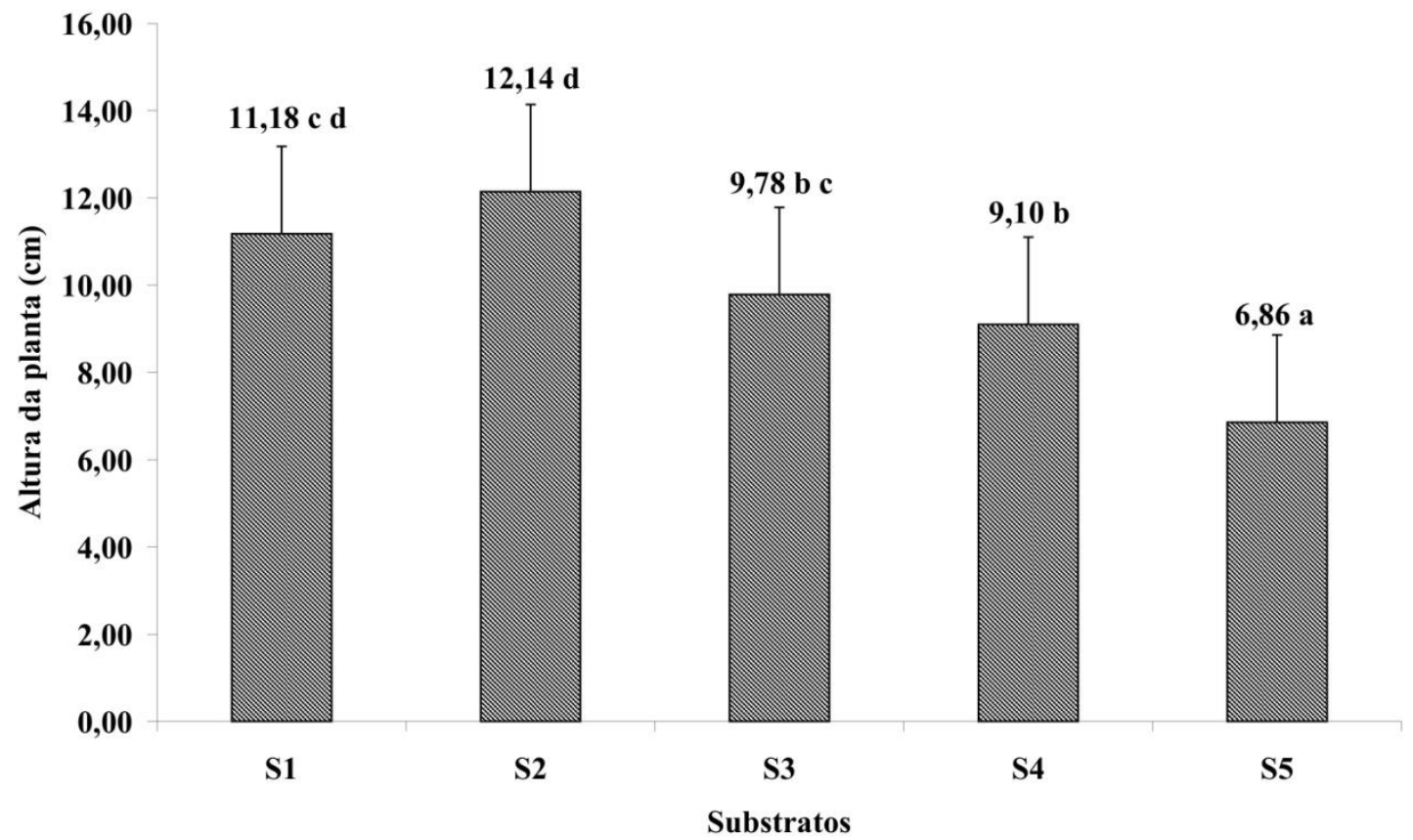

O diâmetro caulinar das mudas de quiabeiro (Figura 2), o substrato $S_{1}, S_{2}$ e $S_{3}$ apresentaram diferenças entre si, porém os Substratos $S_{3}$ e $S_{4}$ e $S_{5}$ são semelhantes pelo teste Tukey ao nível de $5 \%$ de probabilidade. $\mathrm{O}$ substrato $\mathrm{S}_{2}$ proporcionou diâmetro caulinar em mudas de quiabeiro com as maiores médias de 3,85 $\mathrm{mm}$ com superioridade de 25\%, 53\%, $73,32 \%$ e $100,5 \%$ em comparação aos substratos $S_{1}, S_{3}, S_{4}$ e $S_{5}$ com valores de 3,10; 2,32; 2,22 e 1,92 mm, respectivamente. Possivelmente a adição do pó de madeira nos substratos $\mathrm{S}_{3}$ e $\mathrm{S}_{4} \quad \mathrm{eS}_{5}$, material com alta relação carbono/nitrogênio $(\mathrm{C} / \mathrm{N})$, não favoreceu o desenvolvimento das mudas, pois vale ressaltar, que o pó de madeira demanda maior tempo para a estabilização do substrato.

Fato confirmado no experimento que as mudas desenvolvidas no substrato $\mathrm{S}_{5}$, maior porcentagem de pó de madeira, apresentou deficiência visual de nitrogênio, observando-se folhas com tons amarelados verde-claro e plantas pouco desenvolvidas.Isso ocorreu, muito provavelmente, em função do húmus de minhoca condicionar melhor substrato para o desenvolvimento das mudas por possuir maior teor de matéria orgânica o que condicionou como consequência o fornecimento de mais nutrientes como o nitrogênio, fósforo, enxofre e micronutrientes pela decomposição, pelo processo de mineralização e absorção no húmus 
(CASTRO et al., 2001), aumento da capacidade de troca de cátions; melhoria das qualidades físicas do solo, como formação de agregado estáveis, diminuição da densidade do solo, aumentando a aeração do solo, aumento da capacidade de infiltração e armazenamento de água (MESQUITA et al, 2012). Resultado semelhante foi obtido por Pereira et al. (2001), que observaram maiores alturas de mudas de quiabeiro em substrato com 100\% de composto orgânico bovino.

Figura 2. Diâmetro caulinar de mudas de quiabeiro em função de diferentes substratos. (médias seguidas da mesma letra não difere entre si pelo teste tukey/p<0,05) UEPB, Catolé do Rocha-PB, 2014

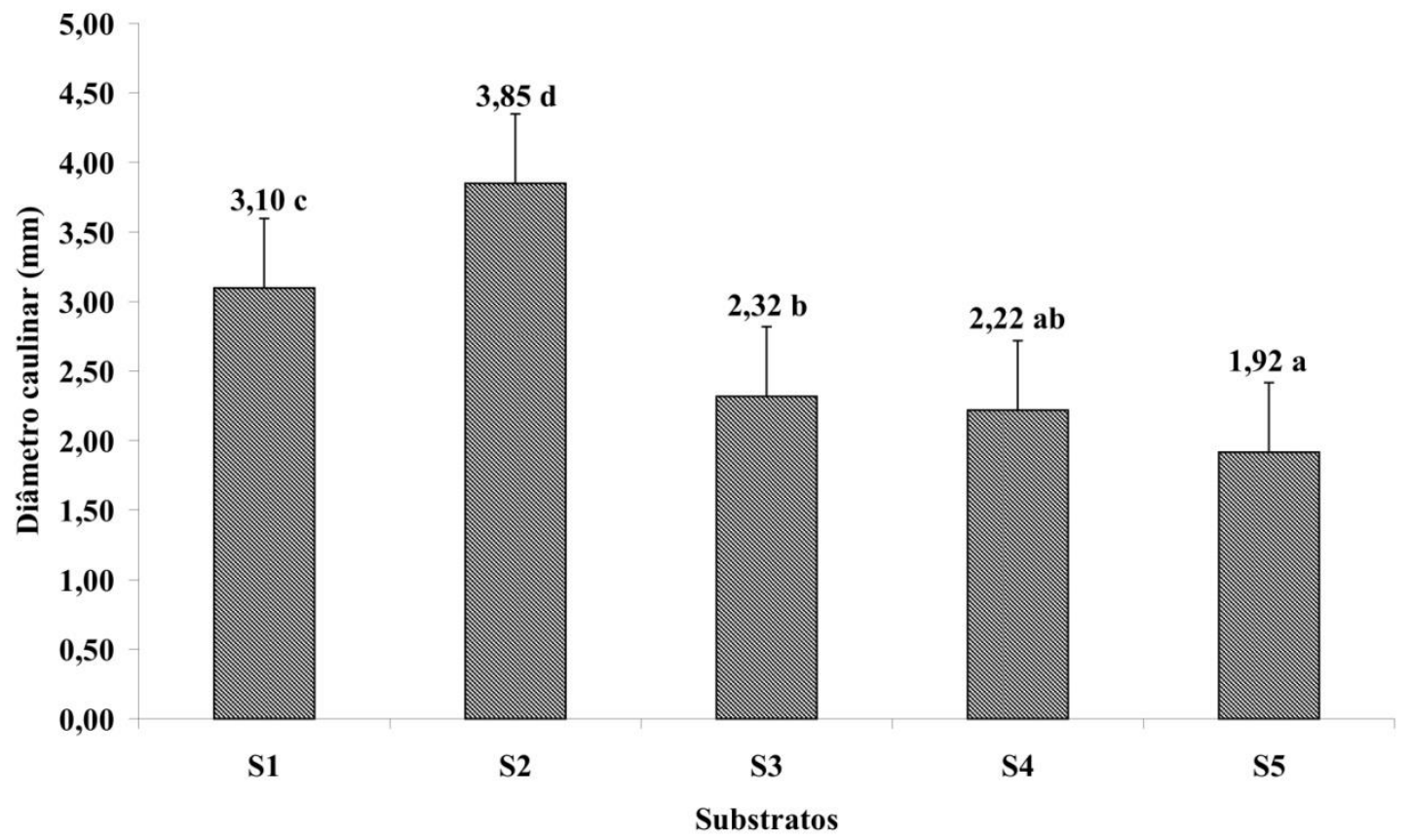

$\mathrm{O}$ substrato $\mathrm{S}_{5}$ com maior percentagem de pó de madeira $(75 \%)$ não apresentou resultados satisfatórios quando se refere à altura da planta, diâmetro Caulinar e área foliar de mudas de quiabeiro com menor média de $10,95 \mathrm{~cm}^{2}$ conforme se observa na Figura 1, 2 e 3,mesmo sem diferença estatística para os substratos $S_{3}$ e $S_{4}$, fato confirmado por Neves et al.2007 que ao avaliarem a germinação de sementes de Moringa oleifera Lam. constataram que o substrato contendo $75 \%$ areia $+25 \%$ pó de madeira proporcionou um significativo atraso na emergência das plântulas da referida espécie. Este resultado insatisfatório pode estar relacionado à sua alta relação $\mathrm{C} / \mathrm{N}$ e baixos teores de nutrientes, o pó de madeira precisa passar por processo de compostagem e/ou repouso e enriquecimento nutricional. A maior 
média foi observada com o substrato $S_{2}$ com média de $121,12 \mathrm{~cm}^{2}$, diferente dos demais tratamentos pelo teste Tukey $(\mathrm{P}<0,005)$.

O húmus de minhoca é um substrato que possui boa retenção de umidade, alta porosidade e baixa densidade, o que muitas vezes, proporciona maior facilidade para as mudas, proporcionando maior uniformidade na oferta de água para o crescimento das mudas. Neste mesmo sentido, Souza et al. (2014), os quais constatarem que o substratos contendo húmus de minhoca na sua composição proporcionou melhor desempenho em mudas de quiabeiro.

Figura 3. Área foliar de mudas de quiabeiro em função de diferentes substratos. (médias seguidas da mesma letra não difere entre si pelo teste tukey/p<0,05) UEPB, Catolé do Rocha PB, 2014

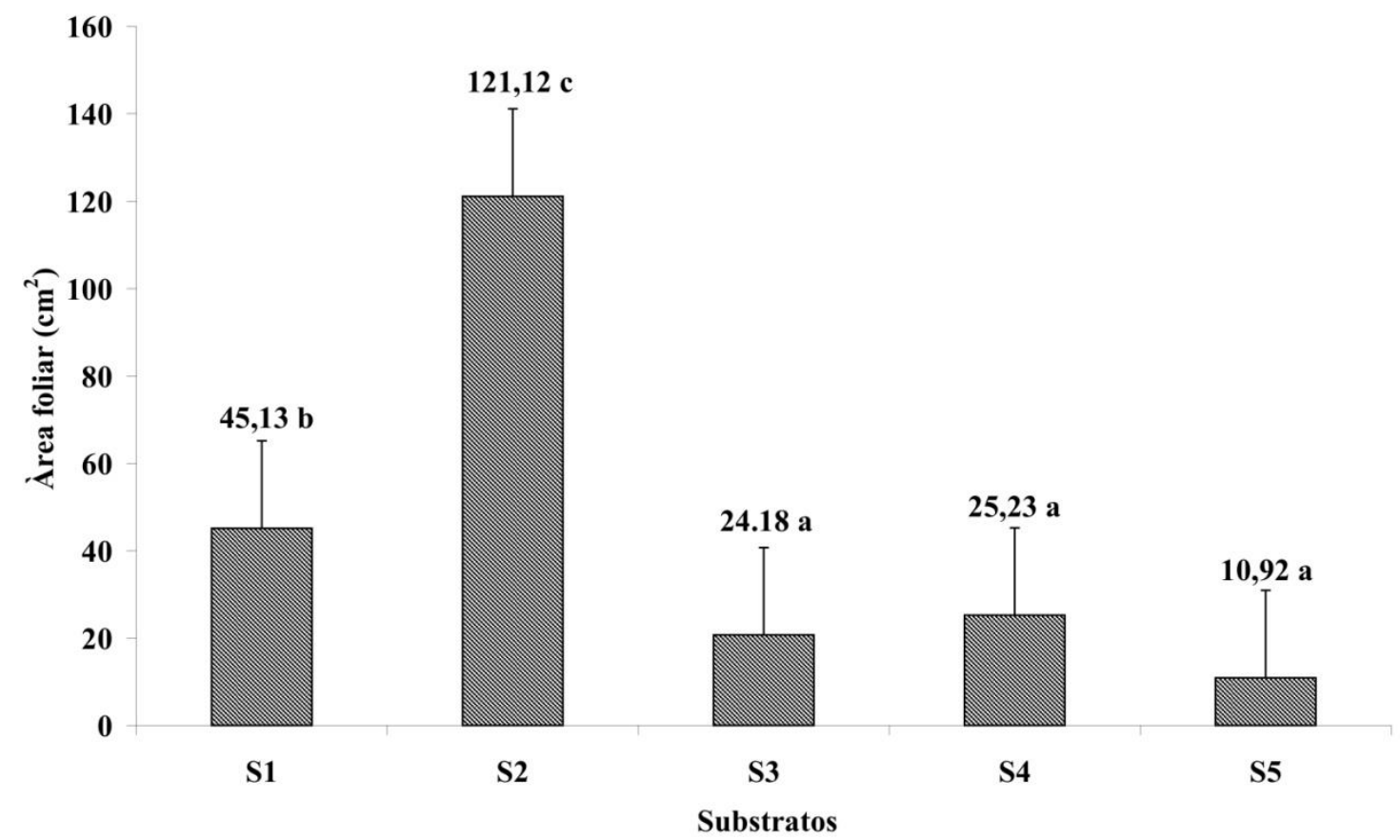

Na Figura 4 são apresentados os resultados da influencia dos compostos utilizados, onde é possível observar que a matéria seca da parte aérea das mudas de quiabo cultivado no substrato $\mathrm{S}_{5}$ com maior porcentagem de pó de madeira na composição apresentou resultados inferiores aos demais tratamentos com média de $0,10 \mathrm{~g}$ planta $^{-1}$. Para esta variável e o substrato contendo húmus $(100 \%)$ apresentou maior média de $0,69 \mathrm{~g}$ planta ${ }^{-1}$ melhor desempenho das mudas de quiabo, deferindo estatisticamente dos demais tratamentos pelo teste Tukey $(\mathrm{P}<0,05)$, com isso, o húmus de minhoca melhora as propriedades físico- 
químicas deste substrato, que possibilitam uma alta capacidade de retenção de água e condições ideais de aeração, o que a torna adequada para a utilização a produção de mudas, inclusive do quiabeiro. Resultados semelhantes foram observados por Souza et al. (2014) verificaram maior peso do caule em mudas de quiabeiro com de $0,16 \mathrm{~g} \mathrm{planta}^{-1}$ formado com substrato contendo húmus na sua composição. O referido autor afirmar que está superioridade pode estar relacionado ao alto teor de matéria orgânica que consequentemente apresenta também alta capacidade de trocas de cátions, gerando maior número de cargas negativas para agregar os cátions possibilitando maior disponibilidade de nutrientes na solução do solo, consequentemente elevando a absorção desses minerais pelas raízes das plântulas.

Figura 4. Materia seca parte aérea em mudas de quiabeiro em função de diferentes substratos. . (médias seguidas da mesma letra não difere entre si pelo teste tukey/p<0,05) UEPB, Catolé do Rocha PB, 2014

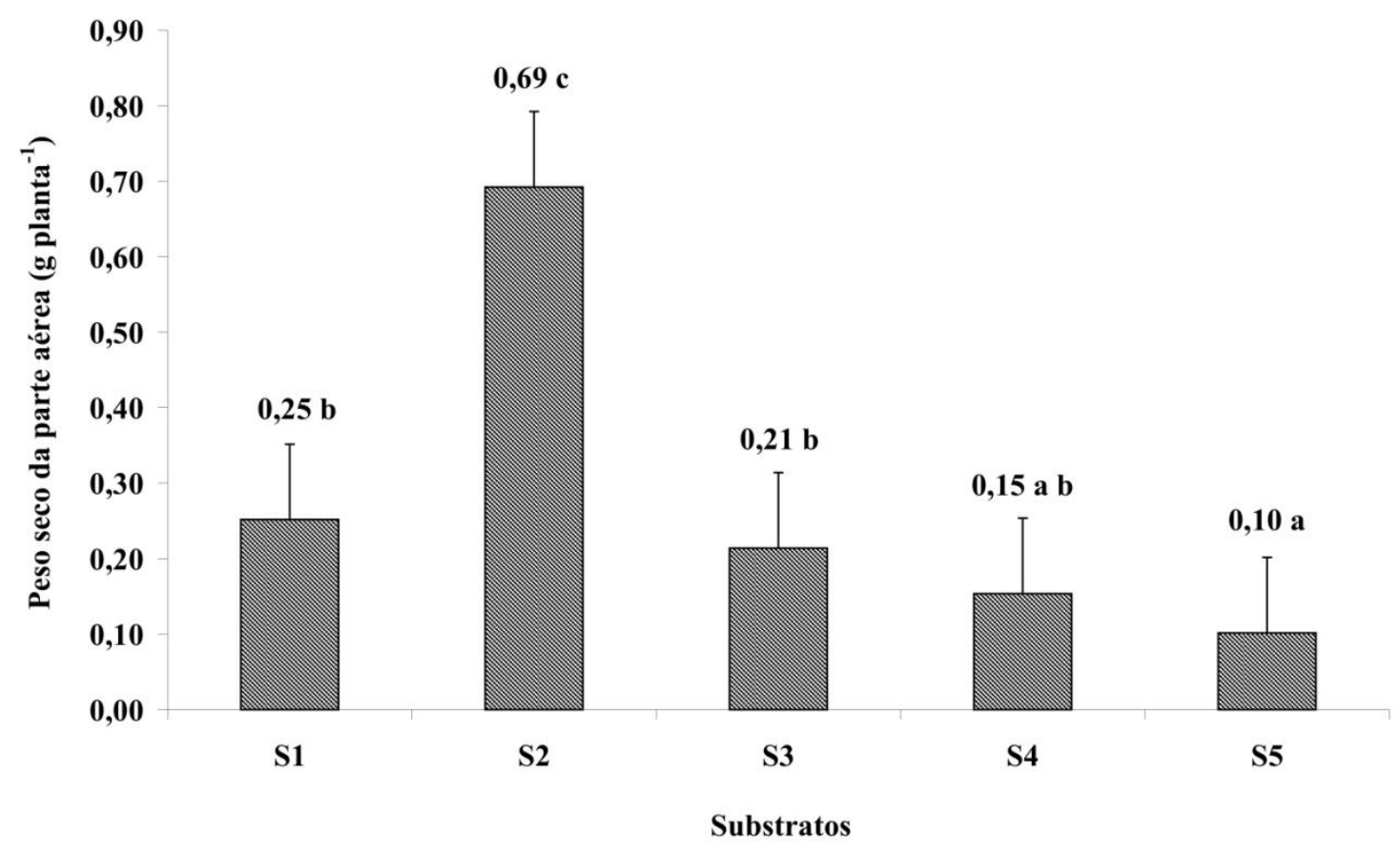

A produção de biomassa seca, apesar de ser um método destrutivo, indica a rusticidade das mudas e pode ser utilizado para estimar a sobrevivência e o crescimento inicial das mudas no campo (CALDEIRA et al., 2008; GOMES et al., 2002; OLIVEIRA et al. 2014); verifica-se que as maiores médias de peso seco raiz das mudas de quiabeiro foram registradas no substrato $\mathrm{S}_{2}$ com $100 \%$ de húmus na sua composição com média de $0,17 \mathrm{~g}_{\text {planta }}{ }^{-1}$, sem diferirem do substrato $\mathrm{S} 1$, mas estatisticamente diferente dos substratos $\mathrm{S}_{3}, \mathrm{~S}_{4}$ e $\mathrm{S}_{5}$, pelo 
teste Tukey $(\mathrm{P}<0,05)$. Para o substrato $\mathrm{S}_{5} \operatorname{com} 75 \%$ de pó de madeira na sua formulação foi registrado a menor média de 0,0 $3 \mathrm{~g} \operatorname{planta}^{-1}$ (Figura 5) (Figura 5). Resposta semelhante com relação ao substrato $S_{2}$ foi verificado por Oliveira et al. (2014) e Souza et al. (2014) que detectaram maiores médias na proporção $40 \%$ e $100 \%$ na formulação dos substratos em mudas de goiabeira e quiabeiro, respectivamente.

Figura 5. Peso seco de raiz em mudas de quiabeiro em função de diferentes substratos. (médias seguidas da mesma letra não difere entre si pelo teste tukey/p<0,05) UEPB, Catolé do Rocha PB, 2014

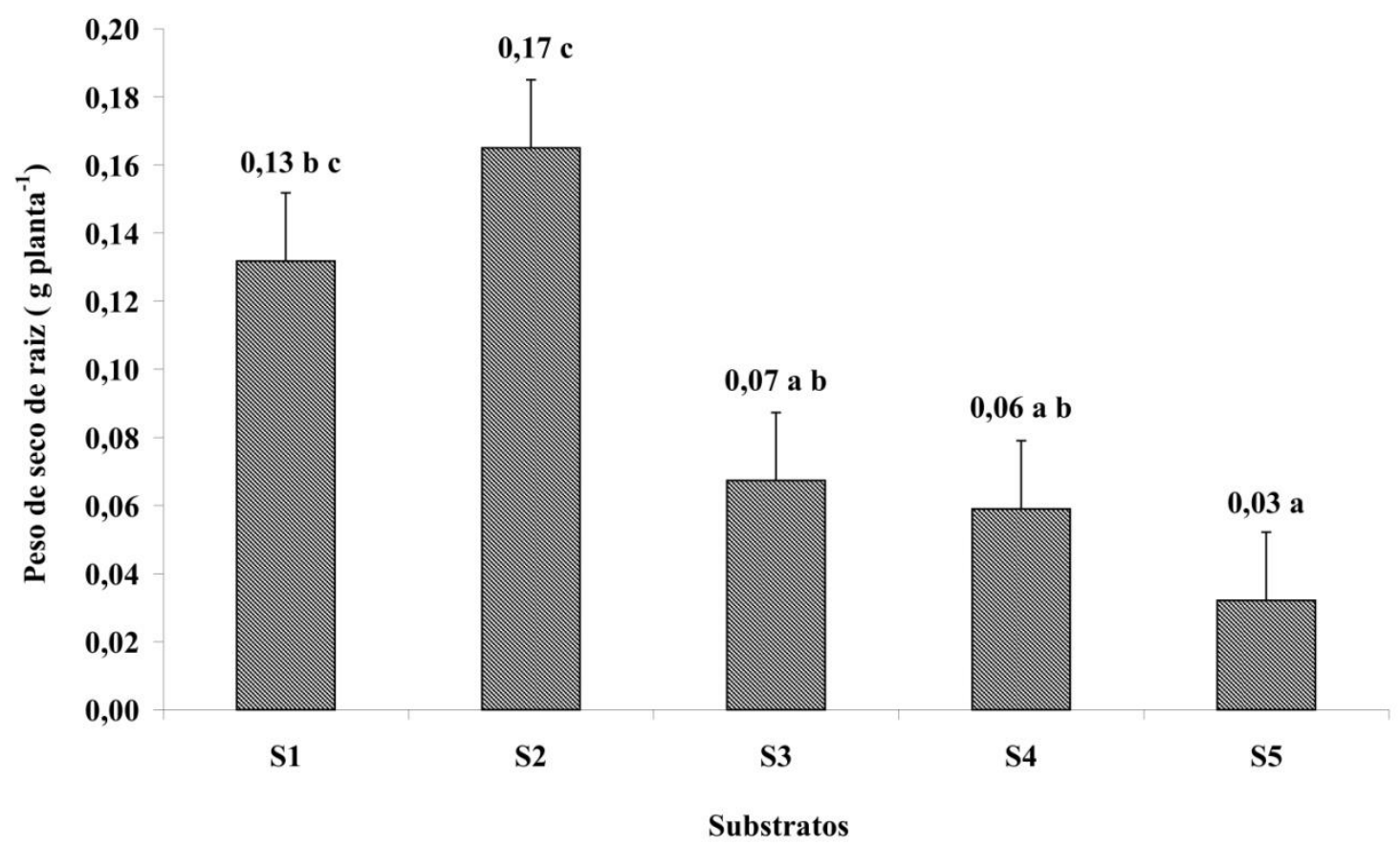

As melhores respostas para o peso seco total em mudas de quiabeiro (PST), de acordo com a Figura 6, foram obtidas nos substratos $S_{1}$ e $S_{2}$ com combinações de solo + húmus de minhoca proporção $1: 1 ; 100 \%$ de húmus de minhoca. Pelas análises de solo e do húmus de minhoca (Tabela 1 e w), observa-se que estes tratamentos apresentaram nutrientes em bons níveis, podendo também estar relacionado com uma maior retenção de umidade, o que contribuiu para um melhor desenvolvimento das mudas. Já os menores valores para está variável foram obtidos no substrato $S_{5}$ com na sua composição.

Uma explicação para esse menor valor, o substrato $S_{5}$ continha a maior porcentagem de pó de madeira (75\%), possivelmente, o tempo de repouso de 30 dias antes da semeadura não foi suficiente para a completa mineralização do material que possui alta relação carbono/nitrogênio $\mathrm{C} / \mathrm{N}$, necessitando de suprimentos extras de nutrientes para completar a 
mineralização, influenciando e desequilibrando o crescimento inicial das mudas de quiabeiro, como relatado por Costa et al. (2009) em experimentos realizado com mudas de mamoeiro. Outra explicação pode ser à disponibilização mais lenta dos nutrientes com os substratos contendo pó de madeira na composição.

Figura 6. Peso seco total em mudas de quiabeiro em função de diferentes substratos. (médias seguidas da mesma letra não difere entre si pelo teste tukey/p<0,05) UEPB, Catolé do Rocha PB, 2014

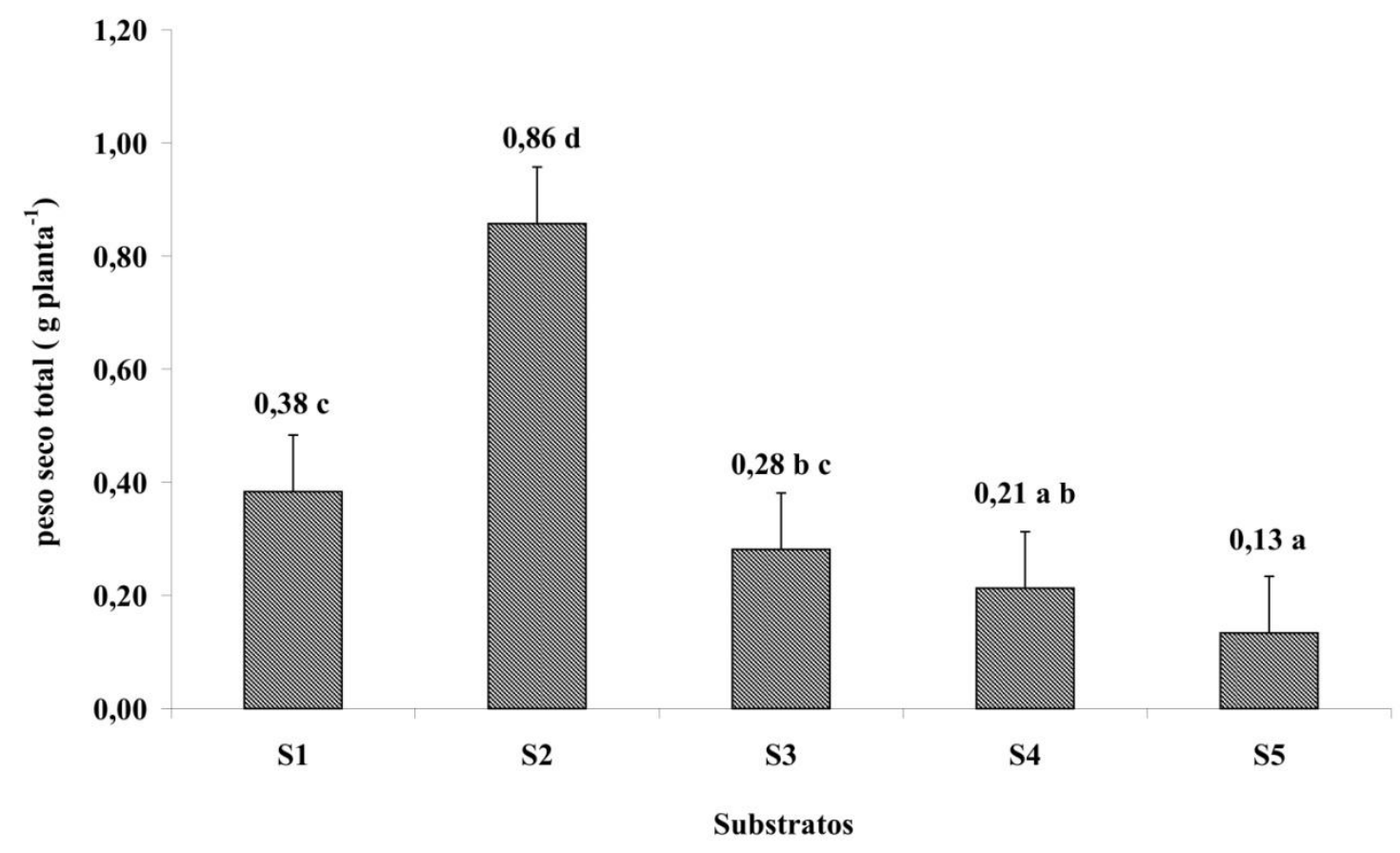

Os substratos $S_{4}$ e $S_{5}$ apresentaram a relação raiz e parte aérea na ordem de 0,62 e 0,78 $\mathrm{g} \mathrm{g}^{-1}$ em mudas de quiabeiro, respectivamente. Esses valores ficaram um pouco acima do considerado adequado, indicando uma proporção inadequada entre o desenvolvimento da raiz e o da parte aérea da planta (Figura 7), ou seja, quando a relação é alta, o que é comum em ambientes de baixa fertilidade, o que pode ser uma estratégia da planta para retirar o máximo de nutrientes nessa condição (COSTA et al., 2005). Para Barbosa et al. (1997), os valores relativamente baixos da relação MSR/MSPA são indicativos de proporção adequada entre o desenvolvimento da raiz e o da parte aérea da planta, sendo esta uma característica para a escolha de mudas de boa qualidade.

Daniel et al. (1997) mencionam que essa razão deve ser de 0,50, entretanto, Fernandez (2002) detectou que a manutenção relativamente adequada do valor de MSR/MSPA está relacionada às melhores condições químicas e físicas dos substratos, devido à presença do 
esterco ou húmus em sua constituição. Por outro lado, os substratos S1, S2, S3 apresentam relação MSR/MSPA adequados com valores de 0,46; 0,58 e 0,59, respectivamente.

Figura 8. Relação raiz parte aérea em função em mudas de quiabeiro em função de diferentes substratos. (médias seguidas da mesma letra não difere entre si pelo teste tukey/p<0,05) UEPB, Catolé do Rocha PB, 2014

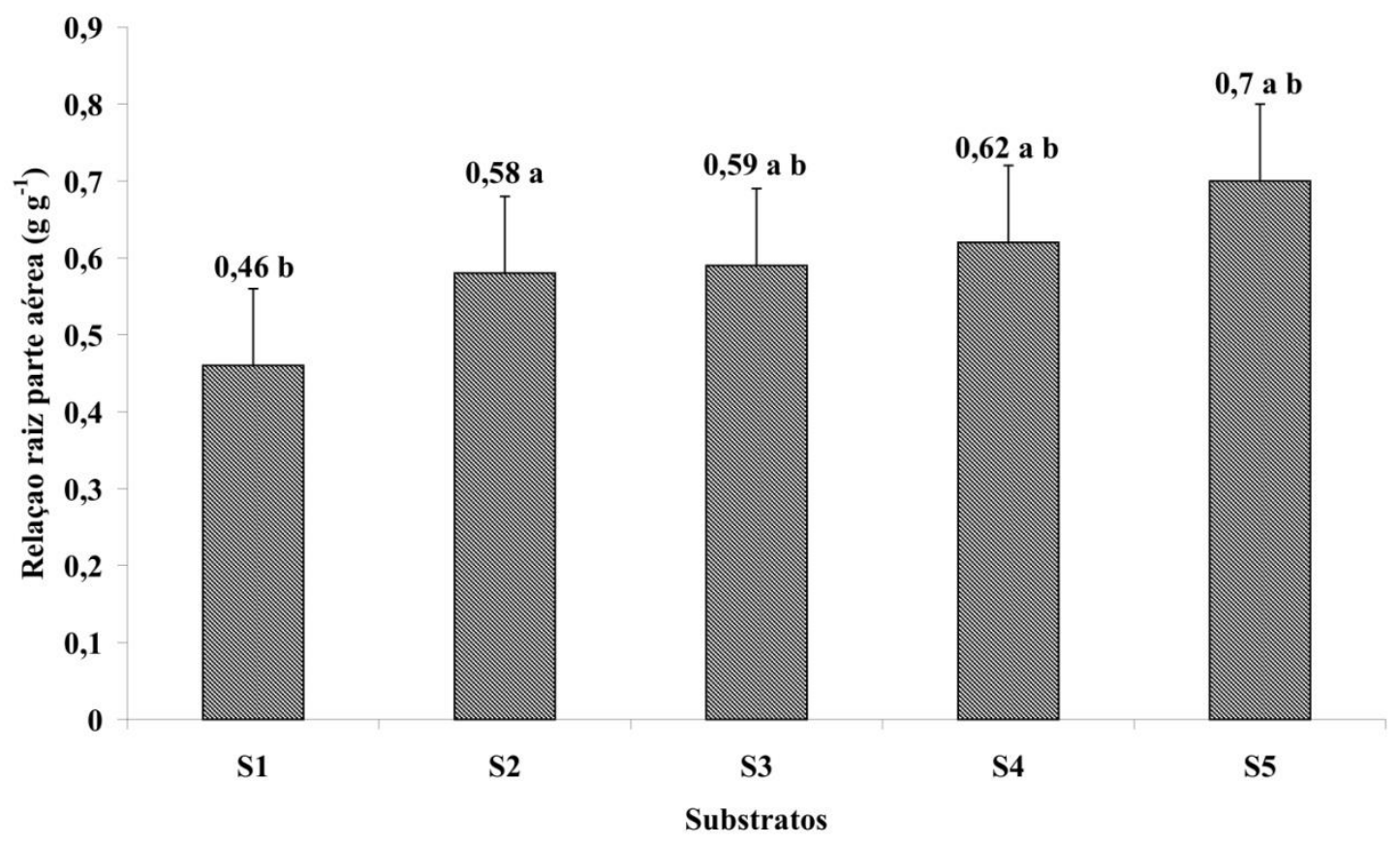

\section{Conclusões}

O substrato $S_{1}\left(100 \%\right.$ solo) e $S_{2}(100 \%$ húmus) de esterco influenciaram de forma positiva o crescimento e biomassa seca em mudas do quiabeiro;

As doses de biofertilizante bovino, independentemente do substrato, não influenciaram a formação de mudas do quiabeiro;

\section{Referências}

BARBOSA, Z.; CARVALHO, J.G.; MORAIS, A.R. Fósforo e zinco na nutrição e crescimento da aroeira-do-sertão (Myracrodruo nurundeuva Fr. All.) I. Características de crescimento das plantas. Ciência e Agrotecnologia, v.21, n.2, p.196-204, 1997. 
CALDEIRA, M. V. W.; BLUM, H.; BALBINOT, R.; LOMBARDI, K. C. Uso do resíduo do algodão no substrato para produção de mudas florestais. Revista Acadêmica: Ciências Agrárias e Ambientais, Curitiba, PR, v. 6, n.2, p. 191-202, 2008.

CARNEIRO, J. G. A. Variações na metodologia de produção de porta-enxerto florestais afetam os parâmetros morfofisiológicos que indicam a sua qualidade. FUPEF: Curitiba, n.12, 1983. p.1-40.

CARNEIRO, S.; GODOY, WI; F., D; WURTZIUS; V. Produção de mudas de alface em diferentes tipos de bandejas com substratos alternativos. 2010. Horticultura Brasileira, V.28: P. 2316-2322, 2010.

CASTRO, M.C.; ALMEIDA, D.L.; RIBEIRO, R.L.D.; GURRA, J.G.M.; FERNANDES, M.C.A. Hortaliças no sistema integrado de pesquisa em produção agroecológica.

Horticultura Brasileira, v. 19, n. 02, 2.001, Suplemento.

CAVALCANTE, L. F.; VIEIRA, M. DA S.; SANTOS, A. F.; OLIVEIRA, W. M.;

NASCIMENTO, J. A. M.. Água salina e esterco bovino líquido na formação de porta-enxerto de goiabeira cultivar Paluma. Revista Brasileira de Fruticultura, v.32, p.251-261, 2010.

COSTA E.; RODRIGUES E.T.; ALVES, V.B.; SANTOS, L.C.R.; VIEIRA, L.C.R. Efeitos da ambiência, recipientes e substratos no desenvolvimento de mudas de maracujazeiro-amarelo em Aquidauana - MS. Revista Brasileira de Fruticultura, Jaboticabal, v.31, n.1, p.236-244, 2009.

COSTA, M.C.; ALBUQUERQUE, M.C.F.; ALBREHT, J.M.; COELHO, M.F.B. Substratos para produção de mudas de jenipapo (Genipa americana L.). Pesquisa Agropecuária Tropical, v.35, n.1, p.19-24, 2005.

DANIEL, O.A.C.T.; VITORINO, A.A.; ALOVISI, L.; MAZZOCHIN, A.M.; TOKURA, E.R.; PINHEIRO; E.F. Souza. Aplicação de fósforo em mudas de Acácia mangium Willd. Revista Árvore, v.21, n.2, p.163-168, 1997.

DANTAS, K. A.; FIGUEIREDO, T. C.: MESQUITA, E. F.; SÁ, F. V. S.; FERREIRA, N. M. Substratos e doses de biofertilizante bovino na produção de porta-enxerto de aceroleira.

Revista Verde de Agroecologia e Desenvolvimento Sustentavel, v.9, n.1, p.157-162, 2014.

ERLACHER, W.A.; OLIVEIRA, F. L.; SILVA, D. M.N.; QUARESMA, M. A.L.; CHRISTO, B. F.Produção de mudas de hortaliças de fruto a partir de substratos formulados com caroço de açaí. In: CONGRESSO BRASILEIRO DE AGROECOLOGIA, 8,2013, Porto Alegre. Resumos... Porto Alegre: Cadernos de Agroecologia, v. 8, n.2, p 1 -5, 2013

FERNANDEZ, J.R.C. 2002. 65 f. Efeito de substratos, recipientes e adubação na formação de mudas de mangabeira (Hancornia speciosa). Dissertação (Mestrado) Universidade Federal de Mato Grosso, Cuiabá:, 2002.

FERREIRA, D. F. Sisvar: a computer statistical analysis system. Ciência e Agrotecnologia, v.35, n.6, p.1039-1042, 2011

GALATI, V.C.; ALVES, A.U.; GALATI, V.C.; CECÍLIO FILHO, A.B. Crescimento e acúmulo de nutrientes da cultura do quiabeiro. Semina: Ciências Agrárias, Londrina, 2013. 
GOMES, J. M.; COUTO, L.; LEITE, H. G.; XAVIER, A.; GARCIA, S. L. R. Parâmetros morfológicos na avaliação da qualidade de mudas de Eucalyptus grandis. Revista Árvore, Viçosa, MG, v. 26, n. 6, p. 655-664, 2002.

MALAVOLTA, E. ABC da adubação. São Paulo: Agronômica Ceres, 292p.1989.

MENEZES JÚNIOR, F.O.;FERNANDES, H.S.; MAUCH, C.R. SILVA, J.B. . Caracterização de diferentes substratos e seu desempenho na produção de mudas de alface em ambiente protegido. Horticultura Brasileira,18, n. 3, P.164 -170,2000.

MESQUITA, E.F.; CHAVES, L.H.G.; FREITAS, B.V.; SILVA, G.A.; SOUSA, M.V.R.; ANDRADE, R. Produção de mudas de mamoeiro emfunção de substratos contendo esterco bovino e volumes de recipientes. Revista Brasileira de Ciências Agrárias, Recife, v.7, n.1, p.58 $-65,2012$

OLIVEIRA, F.T.; HAFLE. M.; MENDONÇA, V.; MOREIRA, J.N.; PEREIRA JÚNIOR, E.B.; MARACAJÁ, P. Produção de mudas de goiabeira com diferentes fontes e proporções de adubos orgânicos.Revista Verde de Agroecologia e Desenvolvimento Sustentável, Pombal, v 9., n. 2 , p. 111 - 116, 2014

PEREIRA, N.S.; BEZERRA, F.C.; ROSA, M.F. Produção de mudas de quiabeiro (Abelmoschus esculentusL. Moench) em substratos à base de pó de casca de coco verde. 2Embrapa Agroindústria Tropical: Fortaleza, V. 60., p .511-110,2001

SÁ, F. V. S.; MESQUITA, E. F.; BERTINO, A. M. P.; SILVA, G. A.; COSTA, J. D. Biofertilizantes na produção hidropônica de porta-enxerto de mamoeiro. Revista Verde de Agroecologia e Desenvolvimento Sustentável, v.8, n.3, p.109-116, 2013.

SOUZA, F.C.A.; SOUZA, J.A.M.; PIRES, E.S.; ALVES, J.D.N. Produção de mudas de quiabeiro em estufa com diferentes substratos orgânicos. Nucleus, v.11, n.1,Pp. 73 - 82, 2014.

TRINDADE, A.V.; FARIA, N. G.; ALMEIDA, F. P. Uso de esterco no desenvolvimento de mudas de mamoeiro colonizados com fungos micorrízicos. Pesquisa Agropecuária Brasileira, v.35, n.7, p.1389-1394, 2000.

VAIRO, A. C. S.; AKIBA, F. Biofertilizante líquido: uso correto na Agricultura alternativa. Imprensa. Universitária. Seropédica 1996, 35 p

VERAS, L.M.; ARAÚJO, D.L.; SILVA, G.S.;M. FILHO, J.S.; ANDRADE, R. Efeito do biofertilizante e de volumes de substrato no desenvolvimento de mudas de caju. Revista Verde de Agroecologia e Desenvolvimento Sustentável, Pombal,v. 9, n. 2, p. 325-332, 2014.

ZIETEMANN, C.; ROBERTO, S. R. Produção de mudas de goiabeira (Psidium guajava L.) em diferentes substratos. Revista Brasileira de Fruticultura, v.29, n.1, p.137-142, 2007 